\title{
Porchat, a diaphonía e o torvelinho do fenômeno no neopirronismo
}

\author{
Hilan Bensusan \\ Universidade de Brasília (UNB)
}

\begin{abstract}
RESUMO
Neste texto examino algumas consequências da afirmaçáo de Porchat de que o fenômeno no neopirronismo não precisa ser precisamente definido. Ao deixar o fenômeno variar ao sabor das circunstâncias, a abordagem de Porchat então parece deixar um dos elementos da dupla articulaçáo que forma a epokhé neopirronista - a aceitaçáo do fenômeno sem que ele comande crenças e que forma um par com a suspensão do juízo acerca do que não é fenômeno - imerso em imprecisóes e, com isso, a posição neopirronista vulnerável. Argumento que esta vulnerabilidade é uma de suas virtudes pois apresenta um ceticismo situado, dependente de circunstâncias variáveis e que combate sistematicamente a ideia de que uma tese que imunize a variabilidade do fenômeno pode ser concebida e eventualmente formulada. Para tanto detenho-me na ideia de que o fenômeno é antes de tudo uma manifestação circunstanciada das coisas e é precisamente a ele, em um irremediável torvelinho, que o neopirronismo é enfaticamente leal.
\end{abstract}

\section{PALAVRAS-CHAVE}

Neopirronismo; Porchat; Fenômeno;

Circunstâncias; Manifestações.

\begin{abstract}
I examine some consequences of Porchat's claim that neo-pyrrhonism needs to provide no precise and worked-out definition of phenomenon. At the face of it, to allow such a crucial notion to be undefined seems to render the neo-pyrrhonist epokhé utterly imprecise - the operation of accepting but not believing in phenomena forms the doubly articulated epokhé together with the suspension of judgment concerning what is beyond the phenomena. This imprecision seems to make neo-pyrrhonism vulnerable. I argue that this vulnerability is one of its chief virtues for it makes sure skepticism is situated, dependent on variable circumstances and opposite to the idea that the variability of phenomena can be immunized. I make use of the idea that phenomenon is above all a situated manifestation of things and it is precisely to it, and to the incorrigible turmoil it engenders, that neo-pyrrhonism is solidly faithful.
\end{abstract}

\section{KEY WORDS}

Neo-pyrrhonism; Porchat; Phenomenon; Circumstances; Manifestations. 


\section{A fenomenologia neopirrônica}

Em suas reflexôes sobre o neopirronismo, Oswaldo Porchat precisou distinguir, com Sexto Empírico, o escopo da suspensão do juízo do escopo do phainómenon (fenômeno). O primeiro âmbito determina aquilo acerca do qual o dogma deve ser evitado e o segundo determina o domínio dos conteúdos que merecem aceitação provisória. $\mathrm{O}$ fenômeno está associado àquilo que guia a ação - mas não requer nele mesmo uma atitude como aquela associada às convicçôes. Os dois procedimentos - a indeterminação entre duas alternativas e a aceitação sem convicção — são fundamentais para o combate neopirrônico ao que há de robusto nas crenças: a determinação de um conteúdo e o compromisso então associado a ele. A epokhé como operação cética é constituída de uma dupla operação, um elemento negativo que é a rejeição do dogma - ao invés de aceitar uma tese ou sua antítese diante da diaphonía, suspende-se o juízo acerca do seu conteúdo - e um elemento positivo que impede que vivamos em permanente suspensão de juízo - há algo, fenômeno, que merece aceitação ainda que não comande uma atitude mais forte, a de crença. A produção de diaphonía é acompanhada por uma aceitação, a aceitação do que está fora do escopo da disputa dos dogmáticos; o neopirronismo chancela a aceitaçáo de um consenso. Porém não é preciso que este consenso seja inabalável. É certo que a diaphonía surge do fenômeno, se nutre dele. Há um sentido mesmo em que quanto mais fenômeno mais diaphonía, mas o neopirronismo nem exorciza o fenômeno e nem o preserva. O fenômeno é tão inevitável quanto a diaphonía; e é matéria-prima sempre abundante no empreendimento cético.

Entendo hoje que esta dupla articulação da operação neopirrônica é sua grande virtude. É uma virtude por vezes difícil de defender; uma razão para a dificuldade é que quando o foco é sobre o princípio que distingue os dois tipos de conteúdo - o que merece aceitação e o que não merece sequer aceitação - a posição pode parecer frágil. No primeiro registro da minha longa e intermitente discussão com Porchat explorei, com Paulo Guimarães de Sousa, esta fragilidade. ${ }^{1}$ Argumentamos que era preciso que houvesse uma distinção de princípio entre os dois conteúdos - aqueles destinados à suspensão de juízo e aqueles que devem ser aceitos como fenômeno uma vez que a arbitrariedade aqui pode ter consequências indesejáveis. Escrevíamos que se apenas seguimos o senso comun - e o que é por consenso tomado como controverso e como objeto de disputa ou é em geral aceito como tal - para estabelecer o que é fenômeno (e o que é dogma), podemos estar prisioneiros de opinióes amplamente aceitas porém infundadas que fazem com que uma maioria se incline a uma direção inapropriada - epistemicamente insustentável ou eticamente condenável. O neopirronismo, é claro, é prisioneiro da opinião da maioria apenas no que tange ao fenômeno, apenas porque ele aceita, e não acredita, aquilo que é consensualmente

1 Esta discussão intermitente durou aproximadamente 20 anos e sua primeira instância impressa foi na revista Discurso, $c f$. Porchat, 1992, Bensuan \& Sousa e Porchat, 1996. Paulo Guimaráes de Sousa é hoje um antropólogo das convicçóes na University College, Dublin. 
acreditado. Nunca é demais ressaltar que aceitar é aqui muito diferente de acreditar. Porém, de todo modo, argumentávamos, o neopirrônico aceita conteúdos apenas por serem consensuais - e isto traz perigos. Trata-se, talvez, nos termos de Michael Frede, dos perigos da vida urbana - que não aparecem ao rústico: aceita-se aquilo que não provoca controvérsia na cidade, aceita-se aquilo que a maioria não apenas aceita mas acredita (Cf. Frede, 1997). No artigo, criticávamos Porchat e o neopirronismo por serem reféns da vida urbana - e aceitarem o que é consensualmente objeto de crença. Sim, a posição neopirrônica tem como consequência ser refém. Achávamos, com certa razão, que era uma lástima que fosse assim.

As respostas de Porchat foram muitas e não vou tentar apresentá-las todas. Interessa-me uma delas apenas, uma reação direta, característica e que guia algumas de suas ideias mais frutíferas sobre o neopirronismo. Ele me disse uma vez: sim, a noção de fenômeno é histórica, nos deixa à mercê dos tempos em que vivemos, é cambiante e não pode ser apresentada de uma vez por todas — e, até por isso, não importa muito que tenhamos uma definição (adequada) de fenômeno. Importa mais, eu entendi, que tenhamos fenômenos; eles são o ponto de partida para a construçáo de diaphonía. Eles são cruciais para a vida filosófica do cético urbano. Estamos todos à mercê do que aparece, estamos todos reféns dos fenômenos - mas o neopirronismo faz uma torção neste estado de coisas, ele prega que não apenas as vidas mas as dúvidas dependem do fenômeno. Nossa atividade de duvidar está situada, localizada, indexada aos outros que nos aparecem, que nos interpelam.

Rejeitar que o fenômeno possa ser definido me parece agora como um passaporte para um ceticismo situado - um passaporte para uma suspensáo de juízo que náo ocorre desde parte alguma, como uma visão em terceira pessoa, mas em função do que é acreditado como consensual no rincão e no período de onde eu duvido. A dúvida tem lastro - como mostra explicitamente Wittgenstein em seu Da certeza (2000). E tem contexto, ponto de partida, alicerce e linhas de sustentação. É a partir do que é tomado como certo - que não é conhecimento e nem sequer comanda crença mas apenas requer certeza - que a dúvida ganha inteligibilidade e que alguma coisa pode ser colocada em questão. A dúvida é uma praga na lavoura das certezas e é por atingi-las que ela termina por incidir sobre justificaçóes. E a certeza náo pode ser identificada senáo desde dentro das formas de vida, desde dentro da convivência com outros argumentadores e com outros sujeitos capazes de crença. Rejeitar a definição de fenômeno é precisamente o que faz o exercício de duvidar do neopirrônico estar atrelado às certezas da vez e, assim, à circunstância de onde a atividade de duvidar começa. A atividade cética é uma atividade situada - e, por isso mesmo, uma atividade irremediavelmente circunstancial. Ela não pode ser alheia a qualquer particularidade. A dúvida e a diaphonía não pairam no ar, elas estáo presas a proposiçóes dobradiças — o fenômeno, como as proposiçôes dobradiças, não pode ser catalogado; quando estamos diante dele, aceitamos o que ele mostra, o que ele faz aparecer. O fenômeno é ele mesmo circunstancial — e a dúvida não pode ser senão igualmente 
circunstancial. Não porque ela pode ser dirimida, mas porque ela é produzida pela diaphonía que é, ela mesma, refém de um ponto de partida.

\section{A produção da dúvida}

Em alguns artigos mais recentes (Bensusan, 2015) e em um capítulo de Being Up For Grabs (Id., 20I6), contrastei o neopirronismo com o que chamei de ontologia da dúvida e que tem coincidências importantes com o que alguns autores entendem como sendo o núcleo central do pirronismo original ${ }^{2}$. A ontologia da dúvida — em suas muitas variedades - postula que não há (apenas) determinaçóes no mundo; a ideia mesma de que o mundo é feito de determinaçóes que não podemos ter acesso jamais se há uma diaphonía incorrigível — como toda genuína diaphonía deve ser também segundo o neopirronismo - mas que persistem determinadas é ela mesma dogmática. Ainda que com um enorme impacto sobre o que conhecemos já que os objetos do conhecimento não são tomados como sendo todos compostos de determinaçóes, a ontologia da dúvida é uma tese sobre o mundo e não sobre o conhecimento humano dele: o mundo é composto por indeterminaçôes. Como corolário, quando estamos diante de uma indeterminacão a atitude epistêmica mais recomendável é aquela da dúvida. Quando duvidamos, segundo a ontologia da dúvida, podemos estar em um contato direto com a indeterminação já que há coisas que não são determinadamente de um modo ou de outro, mas são antes indefinidas. A ausência de determinação não é apenas uma marca de um déficit humano — "alguém vê e eu não vejo", na expressão de Wittgenstein (2009, $\$ 352)$ - mas caracteriza a realidade mesma, ela mesma permeada de indeterminação. A ontologia da dúvida postula indeterminações no mundo; agora, algumas variedades dela postulam que tudo é indeterminado enquanto outras entendem que o tabuleiro de interdependências entre determinaçóes e indeterminações é parte do mundo e não apenas uma dimensão do conhecimento humano, algumas variedades entendem que as indeterminaçôes são constituintes mesmas de como as coisas são enquanto outras entendem que as indeterminaçôes são situadas, que as dúvidas são circunstanciadas, atreladas a uma posição. Vale dizer que favoreço as segundas posições em detrimento das primeiras.

A fricção entre a ontologia da dúvida e o neopirronismo permite que tenhamos algumas intuições sobre a natureza (talvez indefinível) do fenômeno. A ontologia da dúvida está próxima da posição que Enesidemo termina por adotar no fim da sua vida e que recebeu uma condenação explícita por parte de Sexto (HP, I). O que me interessa aqui é que Sexto entendeu que Enesidemo terminou por adotar uma posição dogmática — de que há indeterminações no mundo. É certo que a ontologia da dúvida pode reagir acusando a tese — supostamente neopirrônica — de que náo há indeterminaçôes no mundo como sendo igualmente dogmática. Ou, ainda mais diretamente ao ponto, a ontologia da dúvida pode recuar e suspender o juízo quanto

2 Cf. Conche, 1994; Bett, 2000 e Polito, 2004. 
a este dogma que Sexto encontra em Enesidemo (e quanto ao dogma que Enesidemo em reação poderia atribuir a Sexto). Neste caso, haveria uma maneira de, ao mesmo tempo, entender que dúvidas e determinaçóes permeiam o conhecimento humano e, ao mesmo tempo, permeiam o objeto do conhecimento humano. Ou seja, é possível que o ato de duvidar seja o mais epistemicamente apropriado em certas circunstâncias - se as circunstâncias forem de indeterminaçóes. Uma posição informada pela ontologia da dúvida se torna assim mais permeável às circunstâncias das dúvidas; o neopirronismo e a ontologia da dúvida compartilham a necessidade de fenômenos como ponto de partida — circunstanciais, cambiantes e em última instância dificilmente definíveis.

Tanto a ontologia da dúvida quanto o neopirronismo partem do fenômeno e produzem diaphonía. Este procedimento de manufatura - podemos chamar a operação de diaphonização - interessa à ontologia da dúvida porque a diaphonía pode ser precisamente o estado epistêmico mais adequado pelo menos em algumas circunstâncias e interessa ao neopirronismo porque ainda que a diaphonía não seja epistemicamente o estado mais adequado, ele é de algum modo o estado mais recomendável. A ontologia da dúvida pensa que a dúvida é um acerto enquanto o neopirronismo pensa que a dúvida é o que há de mais acertado a fazer. O fenômeno é a matéria prima para a produção de estados epistêmicos em linha com as indeterminaçóes no mundo e assim para alcançar a verdade acerca do que é indeterminado tanto quanto para o aumento do descompromisso com o dogma, descompromisso que precisamente promove a ataraxia neopirrônica. Em todos os casos, o fenômeno é onde a diaphonização começa, onde ela tem lugar. É seu ponto de partida. Porém a operação não salta aos olhos como algorítmica: ela não é manufatura mecanizada, ela depende de estratégias de encontrar alguma lacuna questionável no conteúdo aceito do fenômeno. Se o fenômeno é mutável, histórico, situado e posicionado — indefinível — há sempre a possibilidade de novas diaphonizaçóes. Aquilo que parecia consolidado como fenômeno pode deixar de ser - e o inverso não ocorre uma vez que a diaphonía não precisa ser curada nem pelo neopirrônico e nem pelo ontólogo da dúvida. Ou seja, a diaphonía aumenta a partir do fenômeno, que obtém seus conteúdos através do consenso que a vida comum produz. Não há operação inversa à diaphonização, mas há operação de produçáo de fenômenos — ponto de partida de qualquer diaphonía situada. A friçção com a ontologia da dúvida faz ver que tanto para ela quanto para o neopirronismo o fenômeno é ponto de partida incontornável - a dúvida é refém das certezas, daquilo que é dado como consensual em um momento dado e com todas as fragilidades que fazem com que aquilo que aparece deixe de aparecer.

É precisamente por causa do caráter ubíquo e imprevisível da diaphonização que surgem iniciativas como a ciência da dúvida. Independentemente do estatuto das teorias científicas estabelecidas de acordo com o neopirronismo - se de fato elas formam o fenômeno - elas podem ser consideradas em geral consensuais e estáo fora da diaphonía. Na medida em que a ciência requer consenso, ela coloca seus 
conteúdos fora do âmbito das controvérsias, fora das disputas em que mais de uma voz pode ser ouvida. A ciência pelo menos nos últimos séculos tem procurado blindar suas teorias estabelecidas de dúvidas permanentes reservando eventuais dúvidas a episódios de revolução científica onde uma teoria estabelecida é no limite substituída por outra. A ciência da dúvida é a pesquisa em torno de como encontrar dissenso nas teorias científicas estabelecidas - inicialmente acerca do tabagismo ou do aquecimento global antrópico mas atingindo muitas outras áreas inclusive a postulação de um terraplanismo contemporâneo em linha com crenças religiosas ${ }^{3}$. A diaphonizaçáo pode ser patrocinada com o objetivo de tirar algum conteúdo do âmbito do fenômeno - gerar dúvidas sobre as mudanças climáticas provocadas pelo uso de combustíveis fósseis ou sobre o efeito nocivo do cigarro sobre humanos. A ciência da dúvida não tem escopo definido, como o fenômeno, ela não pode ter seu âmbito delimitado de uma vez por todas. Ela é cambiante, histórica, situada. Vale dizer que a ciência da dúvida é um tormento quando queremos certezas - ela se propóe a erodir o que parece como deve fazer a diaphonizaçâo, ela se propóe a colocar em questão, a apresentar alternativas, a produzir discordância. E, como disse, porque o fenômeno é indefinível, a diaphonização pode vir de qualquer parte.

Entretanto, ela precisa ser bem feita. É preciso, para a operação se levada a cabo apropriadamente, não apenas que outra voz seja ouvida — diaphonía não é apenas discordância ${ }^{4}$. Ela precisa mostrar através de outra voz que nenhuma voz tem razão suficiente para ser sustentada. É preciso que uma cunha seja introduzida entre um conjunto de crenças e sua justificação - ou, posto em termos mais próximos da ontologia da dúvida, é preciso que uma cunha seja introduzida entre um conjunto de determinaçóes e aquilo que o determina. Em qualquer caso, o procedimento de diaphonização é um procedimento de exposição da contingência: pode ser que a crença seja verdadeira, como pode ser que alguma coisa seja o caso, mas não há nada que suficientemente determine que seja assim. Ou seja, o esforço do procedimento de erosão do consenso (no fenômeno) é precisamente o de demolição das supostas razóes. A ciência da dúvida - e toda atmosfera de pós-verdade na qual em geral ela se apresenta na esfera pública - muitas vezes se limita a apresentar outras vozes; diaphonía, contudo, não é balbúrdia mas gritaria de vozes mutuamente excludentes. É preciso que não haja mais razóes em favor de uma das alternativas - e por ter que alcançar esta equipotência de alternativas a partir dos fenômenos é que a diaphonização não pode ser, pelo menos facilmente, transformada em um procedimento algorítmico.

\footnotetext{
3 Cf. Oreskes \& Conway, 2010.

4 A emergência da ciência da dúvida provocou um resurgimento do interesse no problema da demarcação que estava dormente desde os anos 1970. Ver, por exemplo, Pagliucci \& Boudry, 2013.
} 


\section{O fenômeno indefinivel}

A noção de fenômeno indefinível faz portanto com que a manufatura da dúvida não possa ser feita de uma vez por todas, como um procedimento algorítmico. Se o fenômeno estiver associado, por exemplo, a uma sensorium humano - e a ideia de que apenas algumas aparências são aparências para esta sensibilidade - tudo aquilo que é extra-sensível está associado ao que transcende ao fenômeno. Neste caso, o fenômeno estaria associado a um conjunto de capacidades da sensibilidade humana e algo como uma filosofia transcendental poderia ser invocada para traçar pelo menos em princípio as fronteiras do que é fenomênico. De uma certa maneira, as consideraçôes do empirismo moderno que abriga questôes céticas com respeito ao que está para além do que pode ser observado - consideraçóes que encontramos em Berkeley que rejeita como dogma a crença na matéria, em Hume que suspende o juízo sobre relaçôes causais com base no que está disponível à observação e em Kant que rejeita a possibilidade de conhecimento do que é transcendente ao âmbito do fenômeno - partem da pressuposição de que aquilo que aparece é apenas sensível e, portanto, pode ser pelo menos objeto de um esforço de definição. Se, por exemplo, o fenômeno for entendido como intuição sensível — ou como ideias dos sentidos - uma definição já pode ser dada e o que não é fenômeno pode ser entendido como aquilo que transcende as capacidades da percepção. Ainda que alguma indeterminação esteja associada ao que é perceptível, um esquema geral do fenômeno e do que merece suspensáo do juízo pode ser oferecido a partir da ideia de que há limites próprios associados ao que está disponível direta ou indiretamente à percepção sensível. Tudo aquilo que transcende o fenômeno — assim definido — seria objeto de suspensão do juízo já que nada pode decidir entre duas ou mais alternativas igualmente fundada nos sentidos.

Aqui poderíamos ter duas posiçóes análogas ao neopirronismo e à ontologia da dúvida: uma diria que não podemos determinar o extra-sensível já que a sensibilidade não nos dá elementos para tanto e outra diria que o extra-sensível não é ele mesmo determinado. Estas posiçóes podem ser acolhidas por variantes das doutrinas de Kant no primeiro caso e por algumas alternativas empiristas no segundo caso - a ideia de que nada é determinado senão aquilo que é observável. Mas importa para mim aqui apenas apontar para o contraste entre estas posiçóes de um lado e o neopirronismo (e a ontologia da dúvida) de outro. Tais posiçôes aderem à ideia de que o fenômeno aquilo que aparece — pode ser pelo menos em princípio definido e, assim, demarcado e separado de todo o resto. É possível, assim, determinar um âmbito acerca do qual cabe a suspensão do juízo em contraste com um outro onde caberia a aceitaçáo da aparência como aparência. Em contraste, sem esta definição em princípio, o trabalho de diaphonização fica sendo inteiramente artesanal. Se o fenômeno não pode ser definido, não podemos circunscrever o âmbito da diaphonía. A suspensão do juízo ou o acesso à indeterminação tem que ser alcançada caso a caso, questão a questão, dúvida a dúvida. $\mathrm{O}$ trabalho da diaphonizaçâo é o trabalho do tráfico de razóes: da análise da suficiência de cada argumento em cada caso. Não há atalho. 
Que consequências têm a tese de que o fenômeno é indefinível? Em geral pensamos o fenômeno como a nossa aparência, como aquilo que nos aparece, como aquilo que nós tomamos como aparente, como aquilo que nos parece. O parecer é neste caso entendido como aquilo que nós conseguimos captar, aceder, alcançar. O fenômeno é pensado em relação a nós e nossas habilidades - e é por isso que parece que um estudo (transcendental) das nossas habilidades, por exemplo na forma de faculdades, pode definir as condiçóes de possibilidade da aparição do fenômeno. Entendido assim, parece que o fenômeno depende de nós, não há nele uma dependência da coisa que nos aparece como fenômeno. Se ele é de alguma maneira associado a nós - e, assim, associado ao sujeito que pensa, conhece e teoriza, uma análise da subjetividade permitirá pelo menos um esboço do que está em seu âmbito. Mas a indefinibilidade dissocia o fenômeno não apenas da sensibilidade mas também da própria marca de uma subjetividade. De fato, a indefinibilidade é corolário desta dissociação entre fenômeno e uma esfera separa da subjetividade. Se o fenômeno não é uma segunda criação a partir das determinaçôes possivelmente inacessíveis, ele não pode ser definido a partir de habilidades ou capacidades associadas à sua aparição. A indefinibilidade do fenômeno é tal que ele nem sequer está associado a capacidade alguma - ele é apenas o que se exprime, o que se mostra, o que se manifesta.

\section{Fenômeno, manifestação e epokhé}

Desassociar o fenômeno da subjetividade cria já de imediato não apenas uma ruptura com qualquer sensibilia associada à captura das aparências como também com a ideia mesma do que é concreto - o fenômeno não está circunscrito, por exemplo, ao espaço-temporal. Porchat insiste neste ponto em seu estudo do fenômeno em Sexto Empírico (Porchat, 20I3). O fenômeno é, de alguma maneira, uma parte do mundo, aquilo que se mostra das coisas - aquilo que guia a açáo por meio daquilo que transparece. A aposta cética no fenômeno é a aposta naquilo que está à mostra, que transparece, que se deixa ver em oposição ao que é recôndito, velado, subjacente. É como se houvesse um parentesco entre a atitude neopirrônica e aquela que procura exorcizar a tentação de dissecar os corpos em busca do que subjaze à pele que está à mostra.

Heidegger $(2012, \$ 7)$ fez uma proposta de reinterpretar a ideia mesma de fenomenologia, tal como ela é apresentada por Husserl, para entender que há uma interferência da coisa que aparece naquilo que nos aparece. Não há apenas uma capacidade (e uma incapacidade) de ver, há também uma agência de mostrar (e um protagonismo do esconder). Ele faz isso por meio de uma ênfase na ideia de que fenômeno, mais do que aparência, é manifestação. A fenomenologia se torna então estudo das manifestaçóes, daquilo que é mostrado, daquilo que se revela a nós ainda antes de defendermos uma tese, de construir uma exposição — ou uma teoria, uma doutrina. A manifestação das coisas revela enquanto oculta, enfatiza Heidegger. A manifestação não é uma tese ainda que pode ser um elemento para tanto - ela 
pode ser um elemento para uma doutrina ou uma teoria, como pode ser um elemento para uma ataraxia cética (ou o ponto de partida para o esforço de uma ontologia da dúvida). Mas o fenômeno não é tese (thesis, a palavra grega que Heidegger muitas vezes insinua), é antes um aparecer-e-desaparecer, um mostrar-e-ocultar que estaria mais próximo da physis que faz com que as flores se abram e fechem, que o céu clareie e escureça, que toda coisa se mostre sempre parcialmente, por meio de uma manifestação situada. É esta manifestação situada que seria o fenômeno, ele é aparência apenas em um sentido derivado. Em um sentido mais primordial, a fenomenologia nos leva de volta "às coisas mesmas" na medida mesmo em que a manifestaçáo é constitutiva de como são as coisas - elas têm sua realidade naquilo que elas mostram e naquilo que ela ocultam. E é apenas no meio das coisas que o fenômeno aparece - é apenas em meio a elas que se nota o que está sendo posto à mostra e o que está sendo velado, escondido, deixado de resguardo. Estar à mercê dos fenômenos se desenha então como estar à mercê do movimento das coisas náo enquanto uma inteligibilidade como aquela das crenças que afirmam como elas são - que elas sáo de um modo ou de outro com independência do que elas mostram ou deixam de mostrar. Se as coisas se manifestam em uma proximidade, em um endereço definido, as crenças tratam do que está exposto a um olho que sobrevoa, a uma visão desde parte alguma - o discurso tético, sustentáculo do dogma, é precisamente o discurso que deixa as coisas à mostra ao invés de estar à mercê de como elas se mostram em cada circunstância. Evitar o dogma por meio da dupla articulação neopirrônica é portanto ao mesmo tempo ater-se ao fenômeno enquanto tal e suspender o juízo quando a como as coisas sáo de um ponto de vista de parte alguma. A epokhé é uma atitude de aproximação das coisas em seu movimento próprio de manifestar-se e encobrir-se. A interpretação heideggeriana do gesto fenomenológico em direção às coisas mesmas aproxima também o gesto neopirrônico da aparição das coisas já que este gesto é aquele que pretende distanciar-se por duas vias do ponto de vista que torna possível o dogma.

Heidegger (1994) contrapóe, por exemplo em suas conferências de Bremen, a physis à thesis como uma contraposição da coisa que se manifesta e se esconde ao objeto que fica exposto, que fica como em um mostruário. $\mathrm{O}$ fenômeno, assim, marca que somos reféns das coisas em suas manifestaçóes, elas se manifestam a nós. Esta manifestação faz com que o fenômeno dependa das coisas - e o fenômeno é precisamente o lugar onde as coisas aparecem à nós. $\mathrm{O}$ fenômeno é onde estamos ao sabor das coisas, ao sabor do que aparece e se esconde - é nele que estamos em contato com as coisas. $\mathrm{O}$ fenômeno guia a ação precisamente porque ele é nosso acoplamento às coisas, ele é o que nos posiciona em meio às coisas. Por isso mesmo, o fenômeno não pode ser circunscrito, nele há uma abertura às coisas, nele há uma espera da manifestação das coisas. Se entendemos assim o fenômeno como manifestação, é fácil entender como o fenômeno pode ser situado, posicionado, indexado às circunstâncias. Não podemos, e não precisamos, definir o fenômeno. Não preci- 
sar desta definição é reconhecer que estamos ao sabor das manifestaçôes, para a manufatura das dúvidas como para a construção de teses, de teorias. Ou seja, estamos reféns da circunstância das coisas, daquilo que elas manifestam - a atividade teórica de produzir teses sobre as coisas não nos destaca das circunstâncias em que os fenômenos se manifestam, ao contrário, ela é, para o neopirrônico, também manchada de circunstância. $\mathrm{O}$ fenômeno náo é algo como uma escada que deitamos fora após fazer uso dela. $\mathrm{O}$ neopirronismo pode entáo se entendido precisamente como um clamor para que não exorcizemos o fenômeno em nome de crenças limpas de suas circunstâncias, isentas de endereço, sem traços de suas origens situadas já que só podem ter sido forjadas no meio do torvelinho das coisas. $\mathrm{O}$ neopirronismo surge então como uma defesa dos estados epistêmicos que são reféns da maresia das coisas, da capacidade delas de se manifestarem de diversas e opostas maneiras em função de circunstâncias. (Uma ontologia da dúvida, por sua vez, entenderia que fora das circunstâncias onde se dá o fenômeno, não há senão diaphonía, não há senão indeterminação se retirarmos da realidade a proximidade que requer o fenômeno; fora do turbilhão do fenômeno há indeterminaçóes já que vistas desde parte alguma todas as coisas podem ser de mais de um modo.)

Talvez uma virtude central do neopirronismo tal como o entendia Porchat seja, portanto, precisamente sua vulnerabilidade. $\mathrm{O}$ ceticismo aparece não como um contra-parte igualmente limpo de circunstâncias do projeto de descrever o mundo desde parte alguma - o ceticismo neopirrônico está no meio das coisas, no meio da manifestação delas e refém delas. Não se trata de um ceticismo retirado que duvida desde parte alguma, mas de um exercício da dúvida no meio do torvelinho do fenômeno. A suspensão do juízo está assim em uma continuidade com o apego ao fenômeno - esta outra operação articulada com o esforço por tomar a manifestação como uma manifestação e nada mais é o que completa a recusa do dogma entendido como uma imagem das coisas independente das circunstâncias em que elas se manifestam. O dogma é uma tentativa de arrancar as coisas do torvelinho de suas interaçóes circunstanciais e combatê-lo é mostrar que o fenômeno enquanto tal é em cada caso ponto de partida da epokhé - e não da construção de teses que se afastam do fenômeno. O combate ao dogma por parte do neopirronismo é o combate precisamente à posiçáo que pretende alcançar quem faz uso do fenômeno para transcender sua circunstancialidade e forjar um mostruário de coisas destacadas daquilo que elas circunstancialmente deixam à mostra ou resguardam. $\mathrm{O}$ neopirronismo, em seu combate através de suas duas operaçóes articuladas, é um entrave no caminho em direção à exposição fora de contexto de todas as coisas. Seu combate ao dogma é o combate a uma posiçáo em que tudo pode ser visto desde fora do meandro em as coisas se manifestam.

\section{0 endereço das dúvidas}

Entendendo o fenômeno como alheio à definiçóes e imerso em um torvelinho, o neopirronismo se apresenta como uma continuidade do projeto pirrônico se este é de 
fato próximo daquilo que chamei de ontologia da dúvida. Se o esforço do pirronismo é o de fazer aparecerem as indeterminaçóes por meio da diaphonização a partir do fenômeno, o neopirronismo procura precisamente concentrar-se no fenômeno e afastar-se de qualquer tentação de alcançar um ponto de vista de parte alguma. A ataraxia náo está associada à capacidade de ver tudo sem estar próximo de nada, mas precisamente à inadequaçáo desde esforço de distanciamento fora de qualquer proporçáo. Não é precisamente que muita a diaphonía ocorra no mundo e nem que ela é uma marca da nossa cognição incapaz de aceder às determinaçôes. É que as determinaçóes são uma espécie de deslealdade com o fenômeno. Uma deslealdade com a trela das coisas às suas circunstâncias e que pode ter a forma tanto de uma postulação de algo fixo subjacente às aparências que são manifestaçóes das coisas quanto de uma capacidade humana de alcançar algo fixo por meio de um esforço em direçáo a constituição de uma thesis. A deslealdade está precisamente em procurar deixar de lado o caráter situado e por isso indefinível do fenômeno em favor de um estado epistêmico de suposto repouso em que o vai-e-vém das manifestaçóes se tornem irrelevantes. Ou seja, o neopirronismo se alça contra um regime epistêmico em que é extraído do fenômeno um conjunto de determinações que comande convicção independente de qualquer circunstância. $\mathrm{O}$ apego ao fenômeno - indefinível mas associado ao modo como as coisas se apresentam em cada situação em que elas se apresentem —é talvez a melhor forma de combater a ideia de que há verdades — cognoscíveis ou não — que se erguem por cima das circunstâncias e são independentes delas.

O pirronismo surge então como um pedido de atenção à diversidade de circunstâncias que o fenômeno traz em seu bojo. Segundo Sexto (HP, I), em sua reprimenda a Enesidemo, nem sequer a tese de que tudo é indeterminado deve ser adotada - conquanto é uma tese - por mais que ela pareça estar conectada a transitoriedade mesma do fenômeno. O fenômeno se contrasta com teses - se contrasta com dogmas — já que ele é situado, circunstanciado, localizado. É como se o neopirronismo fosse precisamente esta lealdade aos endereços; ou antes, ao seu endereço de partida. A dúvida é construída a partir de um lugar e é desde um lugar que a discussão com o dogmático tem lugar - e é precisamente a um endereço que o cético quer então trazer o dogmático já que seu ponto de partida não é um ponto a ser abandonado. O cético então diz ao dogmático: apenas sem ver o torvelinho dos fenômenos é que a diaphonía não aparece pois uma atenção ao fenômeno enquanto fenômeno em cada uma de suas manifestações faz com que mais de uma alternativa de tese seja possível. E não porque isto ocorre por princípio sempre, mas porque o cético se dá ao trabalho de produzir a dúvida e propor a suspensão do juízo diante das manifestaçóes no fenômeno.

Que o fenômeno seja situado, é o que garante que ele atende às coisas sem tematizá-las, sem fazer delas objeto de uma tese. O que é ou será o fenômeno, então, pouco importa; importa que o fenômeno seja fiel às manifestaçóes, ao que aparece porque é a partir do que aparece que toda diaphonía se apresenta. A tarefa do neopirronismo (ou da ontologia da dúvida) é estar à altura do fenômeno, à altura das 
indeterminaçóes que nele se insinuam. $\mathrm{O}$ (neo-)pirronismo inaugura uma filosofia - ou uma postura diante da filosofia — que é situada. $\mathrm{O}$ fenômeno neopirrônico é indefinível porque está no meio do torvelinho de nosso contato com o que existe. E este torvelinho é próprio das coisas que existem em meio às outras e assim são circunstanciadas. $\mathrm{O}$ elemento central do gesto cético não é entâo a dúvida, mas precisamente o desmantelamento da posição que torna o dogma possível. Este desmantelamento se dá por uma lealdade ao fenômeno, uma lealdade portanto às circunstâncias - ou não podemos ver as coisas de parte alguma ou não há tal parte alguma de onde se possa ver. Que toda tentaçáo de dogma tenha que ser rebatida com o esforço cético é a mostra de que nem sequer uma teoria geral do fenômeno pode substituir à adesão, em cada casa, ao que aparece como fenômeno.

\section{Referências}

Bensusan, H. e de Sousa, P. A. G. (1994). "Sobre o que não aparece (ao neopirrônico)", in: Discurso 23, p. 53-70.

Bensusan, H. (20I5). "O lugar da suspensão do juízo: neopirronismo e ontologia da dúvida”, in: Smith, P. J. O neopirronismo de Oswaldo Porchat - interpretaçóes e debate. São Paulo: Alameda Editorial, p. 59-76.

Bensusan, H. (2016). Being Up For Grabs. Londres: Open Humanities.

Bett, R. (200o). Pyrrho, his Antecedents, and his Legacy. Oxford: Oxford University Press.

Conche, M. (1994). Pyrrhon ou l'apparence. Paris: Presses Universitaires de France.

Frede, M. (1997). "The sceptic two kinds of ascent and the question of the possibility of knowledge", in: Burnyeat, M. \& Frede, M. (ed.). The Original Sceptics: a Controversy, Indianapolis: Hackett, p. I27-I52.

Heidegger, M. (1994). Bremer und Freiburger Vorträge, in: Gesamtausgabe, Band 79, Frankfurt: Vittorio Klostermann.

Heidegger, M. (20I2). Ser e Tempo. Tradução de Fausto Castilho. Campinas: Editora Unicamp.

Oreskes, N. \& Conway E. (20IO). Merchants of Doubt: How a Handful of Scientists Obscured the Truth on Issues from Tobacco Smoke to Global Warming. London: Bloomsbury Press.

Pagluicci, M. \& Boudry, M. (2013). The Philosophy of Pseudoscience - Reconsidering the Demarcation Problem. Chicago: University of Chicago Press.

Polito, R. (2004). The Sceptical Road - Aenesidemus and the Appropriation of Heraclitus, Leiden: Brill.

Porchat, O. (1992). "Sobre o que aparece". Discurso I9, 1992, p. 83-122.

Porchat, O. (1994). "Resposta a Hilan Bensusan e a Paulo A. G. de Sousa”, in: Discurso 23, p. $7 \mathrm{I}-86$.

Porchat, O. (2013). "A noção de phainómenon em Sexto Empírico", in: Analytica, Rio de Janeiro, v.I7, n.2, p. 29I-323.

Wittgenstein, L. (2000). Da certeza. Tradução de M. E. Costa, Lisboa: Ediçôes 70.

Wittgenstein, L. (2002). "Investigaçôes Filosóficas”, in: Tractatus \& Investigaçôes Filosóficas, traduçẫo de M. S. Lourenço. Lisboa: Calouste Gulbekian. 